${ }^{1}$ Faculdade de Nutrição, Universidade Federal de Alagoas (UFAL), Maceió, AL, Brasil

2 Instituto de Química e Biotecnologia, UFAL, Maceió, AL, Brasil
Correspondência para: Nassib Bezerra Bueno

Laboratório de Nutrição Experimental, Faculdade de Nutrição, Universidade Federal de Alagoas, UFAL, Campus A. C Simões, Cidade Universitária, BR 104 Norte, Km 97

57.072-970 - Tabuleiro dos Martins, Maceió, Brasil nassibbb@hotmail.com

Recebido em 12/Fev/2010 Aceito em 25/Maio/2010

\section{Perfil em ácidos graxos hepáticos de ratos com esteatose induzida pela dieta AIN-93 atenuada pela substituição parcial do óleo de soja por dieptanoína e trieptanoína}

\author{
Hepatic fatty acid profile of rats with AIN-93 diet- \\ induced steatosis attenuated by the partial substitution \\ of soybean oil by diheptanoin and triheptanoin
}

Nassib Bezerra Bueno', Maria Adriana Firmino da Silva', Ingrid Sofia Vieira de Melo', Terezinha da Rocha Ataíde', Suzana Lima de Oliveira', Antônio Euzébio Goulart Sant'Ana²

$\mathrm{E}$ $\mathrm{m}$ estudos anteriores foram relatadas as repercussões metabólicas hepáticas do consumo crônico de dieptanoína e trieptanoína, di e triacilgliceróis homogêneos do ácido enântico (heptanoico; 7:0), discutidas no trabalho de Silva e cols. (1) e, posteriormente, no estudo de Ataíde e cols. (2), que mostraram que esses acilgliceróis exercem um potencial efeito hepatoprotetor contra a esteatose, numa feição dosedependente. O perfil em ácidos graxos $(\mathrm{AG})$ de lipídios dietéticos determina a incorporação e a composição em $\mathrm{AG}$ das membranas biológicas, alterando diversas funções celulares (3), principalmente pela modulação dos AG esterificados aos fosfolipídios de membrana (4). Dessa forma, investigar a repercussão do consumo crônico de dieptanoína e trieptanoína sobre a modulação do perfil em AG dos lipídios hepáticos de ratos e se tal modulação guarda alguma relação com a esteatose apresentada pelos animais reveste-se de particular importância.

Naquele estudo (1), os ratos foram alocados em quatro grupos, nomeados conforme a dieta a que haviam sido submetidos: grupo $\mathrm{TAGC}_{7} 0$, dieta padrão AIN-93 (5), cuja fonte lipídica é o óleo de soja; grupo TAGC $_{7} 30$, dieta com $30 \%$ de substituição do óleo de soja pelo óleo experimental (64\% trieptanoína, 34\% dieptanoína, 2\% monoeptanoína); grupo $\mathrm{TAGC}_{7} 50$, dieta com $50 \%$ de substituição do óleo de soja pelo óleo experimental; e, grupo controle, com ração para roedores Labina ${ }^{\circledR}$. Até os dois meses de idade, os animais dos grupos $\mathrm{TAGC}_{7} 0, \mathrm{TAGC}_{7} 30$ e $\mathrm{TAGC}_{7} 50$ receberam a versão G (growth) da dieta AIN-93; a partir daí até o final do experimento, a versão $\mathrm{M}$ (maintenance).

Os animais dos grupos $\mathrm{TAGC}_{7} 0, \mathrm{TAGC}_{7} 30$ e $\mathrm{TAGC}_{7} 50$, cujos teores lipídicos hepáticos totais foram significativamente superiores aos do grupo controle, apresentaram quadro de esteatose hepática $(\mathrm{EH})$, discutido nos trabalhos de Silva e cols. (1) e Ataíde e cols. (2). O grupo TAGC $_{7} 0$ apresentou o dobro $(80 \%)$ do número de casos graves, graus 4 e 5 , quando comparado ao grupo $\mathrm{TAGC}_{7} 50$ (40\%), conforme estadiamento da $\mathrm{EH}$ em ratos, estabelecido naqueles trabalhos. Os animais do grupo controle não apresentaram EH. Tal achado histológico levou o grupo de pesquisadores a desenvolver o presente estudo, visando determinar se a substituição do óleo da dieta pelo óleo experimental induziu diferenças importantes no perfil em AG dos lipídios hepáticos e se tal perfil guardou relação com a infiltração gordurosa encontrada. 
Para a presente proposta, procedeu-se à extração por solventes orgânicos e à determinação dos lipídios totais dos fígados dos ratos oriundos daqueles trabalhos $(1,2)$, seguidas por saponificação, conforme Gilani e cols. (6). Aos extratos lipídicos, adicionou-se solução de $\mathrm{KOH} 0,1 \mathrm{M}$, e a mistura reacional foi mantida sob refluxo, por 2 horas. O material saponificado resultante foi acidificado com $\mathrm{HCl}$ 0,1 M para obtenção dos AG livres, que foram recuperados com clorofórmio e submetidos à metilação com $\mathrm{BF}_{3}$ em metanol $(14 \%)$, à temperatura ambiente, por 72 horas. O produto reacional foi purificado por cromatografia em coluna de gel de sílica, utilizando-se clorofórmio como eluente, para obtenção dos ésteres metílicos de AG.

O perfil em AG do tecido hepático dos animais foi determinado por cromatografia gasosa de alta resolução dos ésteres metílicos, utilizando-se um cromatógrafo a gás (HP 5890), equipado com uma coluna capilar SP2560 (Supelco; $100 \mathrm{~m}$ x 0,25 mm x 0,2 $\mu \mathrm{m}$ ), acoplado a um detector de ionização de chama. A programação de temperatura foi $130^{\circ} \mathrm{C}(1 \mathrm{~min})$ a $170^{\circ} \mathrm{C}\left(6,5^{\circ} \mathrm{C} /\right.$ $\min ), 170^{\circ} \mathrm{C}$ a $215^{\circ} \mathrm{C}\left(2,75^{\circ} \mathrm{C} / \mathrm{min}\right), 215^{\circ} \mathrm{C}(12$ $\min ), 215^{\circ} \mathrm{C}$ a $230^{\circ} \mathrm{C}\left(4^{\circ} \mathrm{C} / \mathrm{min}\right)$ e $230^{\circ} \mathrm{C}(3 \mathrm{~min})$. As temperaturas do injetor e detector foram de $270^{\circ} \mathrm{C}$ e $280^{\circ} \mathrm{C}$, respectivamente. As amostras $(0,3 \mu \mathrm{l})$ foram injetadas pela técnica de injeção direta. Os AG foram identificados por comparação com cromatograma de padrões de AG metilados e eluídos nas mesmas condições. O projeto de pesquisa foi submetido ao Comitê de Ética em Pesquisa da UFAL, tendo sido aprovado sob o número 001316/2002-30.

Os resultados foram avaliados segundo os pressupostos paramétricos de normalidade (teste de Lilliefors) e homogeneidade das variâncias dos resíduos (teste de Levene). Para os AG que apresentaram resíduos com uma distribuição normal padronizada e homocedásticos, realizou-se análise de variância (ANOVA; $\mathrm{p}<0,05)$ e suas médias foram comparadas pelo teste post-hoc de Tukey-HSD ( $\mathrm{p}<0,05)$. Para os demais AG, utilizou-se o teste de Kruskal-Wallis (teste $\chi^{2} ; \mathrm{p}<0,05$ ) e suas médias foram comparadas pelo teste post-hoc de Nemenyi $(\mathrm{p}<0,05)$. Adicionalmente, foi realizado teste de correlação linear de Spearman entre graus de EH e concentração hepática de AG palmítico e linoleico $(\mathrm{p}<0,05)$.

Diferente dos ácidos heptadecanoico, $\gamma$-linolênico, docosa-hexaenoico, mirístico, pentadecanoico, esteárico e $\alpha$-linolênico, as concentrações hepáticas dos ácidos palmítico, palmitoleico, oleico, linoleico e 11,14,17- eicosatrienoico diferiram significativamente entre os grupos estudados (Tabela 1).

Tabela 1. Valores médios percentuais de ácidos graxos do tecido hepático dos ratos dos grupos $\mathrm{TAGC}_{7} 0, \mathrm{TAGC}_{7} 30, \mathrm{TAGC}_{7} 50$ e controle

\begin{tabular}{|c|c|c|c|c|}
\hline \multirow{2}{*}{$\begin{array}{l}\text { Ácidos graxos } \\
\text { (\%; escores médios) }\end{array}$} & \multicolumn{4}{|c|}{ Grupos } \\
\hline & TAGC $_{7} 0$ & TAGC $730_{7}$ & TAGC $70_{7}$ & Controle \\
\hline Mirístico² & $0,6829^{a}$ & $0,2977^{\mathrm{a}}$ & $0,4414^{\mathrm{a}}$ & $0,0000^{b}$ \\
\hline Pentadecanoico ${ }^{2}$ & $0,0819^{a}$ & $0,0420^{\mathrm{a}}$ & $0,0947^{\mathrm{a}}$ & $0,0000^{b}$ \\
\hline Palmítico² & $21,4709^{a}$ & $7,3253^{c}$ & $13,5460^{b}$ & $5,6234^{c}$ \\
\hline Palmitoleico & $6,1375^{a}$ & $3,2753^{b}$ & $3,0949^{b}$ & $0,0871^{c}$ \\
\hline Heptadecanoico ${ }^{1}$ & $0,1146^{a}$ & $0,0413^{a}$ & $0,0921^{\mathrm{a}}$ & $0,1297^{a}$ \\
\hline Esteárico² & $2,4950^{a}$ & $0,8597^{\mathrm{a}}$ & $2,9555^{\mathrm{a}}$ & $3,8530^{\mathrm{a}}$ \\
\hline Oleico & $18,4260^{\mathrm{a}}$ & $3,1110^{c}$ & $10,3263^{b}$ & $1,9491^{c}$ \\
\hline Linoleico $^{2}$ & $10,8767^{\mathrm{a}}$ & $3,9563^{b}$ & $5,4381^{\mathrm{b}}$ & $2,3593^{b}$ \\
\hline$\gamma$-Linoleico ${ }^{1}$ & $0,3453^{a}$ & $0,1530^{\mathrm{a}}$ & $0,2251^{\mathrm{a}}$ & $0,1886^{\mathrm{a}}$ \\
\hline$\alpha$-Linolênico² & $0,3970^{a}$ & $0,1147^{\mathrm{a}}$ & $0,1906^{\mathrm{a}}$ & $0,0000^{b}$ \\
\hline 11,14,17-eicosatrienoico² & $4,5680^{\mathrm{a}}$ & $1,3430^{\mathrm{b}}$ & $4,4244^{\mathrm{a}}$ & $1,9821^{b}$ \\
\hline Docosaexaenoico $^{1}$ & $1,5606^{\mathrm{a}}$ & $0,0800^{\mathrm{a}}$ & $1,0457^{\mathrm{a}}$ & $0,1530^{\mathrm{a}}$ \\
\hline
\end{tabular}

${ }^{1}$ Letras diferentes nas linhas indicam diferença significativa pelo teste post-hoc de Tukey-HSD $(p<0,05)$.

${ }^{2}$ Letras diferentes nas linhas indicam diferença significativa pelo teste post-hoc de Nemenyi $(p<0,05)$.

Os fígados dos animais que receberam o óleo experimental, grupos $\mathrm{TAGC}_{7} 30$ e $\mathrm{TAGC}_{7} 50$, apresentaram níveis significativamente menores de palmitato e oleato do que aqueles do grupo $\mathrm{TAGC}_{7} 0(\mathrm{p}<0,05)$. Curiosamente, o grupo $\mathrm{TAGC}_{7} 50$ apresentou concentrações mais elevadas desses AG do que o grupo $\mathrm{TAGC}_{7} 30$ $(\mathrm{p}<0,05)$. Com relação ao ácido palmitoleico, os ratos alimentados com o óleo experimental apresentaram valores significativamente menores que aqueles alimentados com dieta sem substituição do óleo de soja, grupo $\mathrm{TAGC}_{7} 0$, e valores significativamente maiores que aqueles do grupo controle $(\mathrm{p}<0,05)$. Foram observados níveis significativamente maiores de ácido linoleico no grupo TAGC $_{7} 0$, em relação aos demais $(\mathrm{p}<0,05)$. O ácido $11,14,17$-eicosatrienoico, por sua vez, não pareceu obedecer a um padrão, pois os grupos $\mathrm{TAGC}_{7} 0$ e $\mathrm{TAGC}_{7} 50$ foram semelhantes entre si, a exemplo do que ocorreu entre os grupos $\mathrm{TAGC}_{7} 30$ e controle (Tabela 1). O perfil em AG das dietas ofertadas aos animais, com aproximadamente $4 \%$ de lipídios totais, encontra-se na tabela 2.

Quanto à repercussão do perfil em $\mathrm{AG}$ das dietas sobre o perfil em AG do fígado dos animais, as concentrações hepáticas dos ácidos palmítico, oleico e 11,14,17-eicosatrienoico poderiam resultar de mecanismos contraditórios associados ao consumo de AG de 
Tabela 2. Valores percentuais aproximados dos ácidos graxos mais abundantes nas dietas oferecidas aos animais dos grupos $\mathrm{TAGC}_{7} 0$, $\mathrm{TAGC}_{7} 30, \mathrm{TAGC}_{7} 50$ e controle

\begin{tabular}{lllll}
\hline \multirow{2}{*}{$\begin{array}{c}\text { Ácidos graxos } \\
\text { (\%) }\end{array}$} & \multicolumn{4}{c}{ DIETAS } \\
\cline { 2 - 5 } & TAGC $\mathbf{7}^{\mathbf{0}}$ & TAGC $\mathbf{7 3 0}$ & TAGC $_{\mathbf{7}} \mathbf{5 0}$ & \multicolumn{1}{c}{ Controle } \\
\hline Enântico & $\mathrm{ND}$ & 30,00 & 50,00 & $\mathrm{ND}$ \\
Palmítico & 9,46 & 5,49 & 2,65 & 24,18 \\
Esteárico & 3,88 & 1,84 & 1,05 & 4,41 \\
Oleico & 15,46 & 8,74 & 5,35 & 32,33 \\
Linoleico & 42,31 & 17,97 & 13,86 & 39,21 \\
Linolênico & 5,98 & 2,78 & 2,08 & ND \\
\hline
\end{tabular}

ND: não detectado.

cadeia média, tais como redução do pool de AG hepáticos, pela rápida $\beta$-oxidação, com liberação de energia (efeito termogênico), e síntese de novo e/ou elongação e dessaturação de lipídios hepáticos, pela formação excessiva de grupos acetila liberados pela $\beta$-oxidação, conforme discutido por Lucena e cols. (7). A resultante desses mecanismos, no presente trabalho, provavelmente sofreu influência das diferentes concentrações de ácido enântico nas dietas experimentais.

O menor consumo de AG de cadeia longa, por sua vez, de maneira geral, parece ter contribuído para a menor concentração desses $A G$ no fígado dos animais submetidos à substituição parcial do óleo de soja pelo óleo experimental. Tais considerações auxiliam o entendimento da relação entre composição em AG da dieta e o quadro de $\mathrm{EH}$, cuja gravidade foi particularmente mais elevada no grupo de animais do grupo $\mathrm{TAGC}_{7} 0$, que recebeu dieta sem adição de ácido enântico. No entanto, questões outras relacionadas à composição da dieta AIN-93, a exemplo do teor de fatores lipotróficos, devem ter exercido papel relevante na indução do quadro de EH, como apontado por Silva e cols. (1), uma vez que os animais do grupo controle não apresentaram $\mathrm{EH}$, apesar do consumo de fontes alimentares de AG de cadeia longa.

No que diz respeito à associação entre o perfil em AG hepáticos e o quadro de $\mathrm{EH}$, podem ser destacados os ácidos palmítico e linoleico, não apenas pelas concentrações observadas, mas, especialmente, por alguns de seus efeitos metabólicos, que guardam uma possível relação com a infiltração gordurosa. Na presente investigação, foi encontrada correlação linear positiva significativa entre a concentração de ácido palmítico e graus de EH $\left(\mathrm{r}_{\text {Spearman }}=0,52 ; \mathrm{p}<0,01\right)$. No entanto, o mesmo não foi observado para o ácido linoleico $\left(\mathrm{r}_{\text {Spearman }}=0,34\right.$; $p \geq 0,05)$.
Um dos fatores que parece contribuir de maneira importante para a patogênese e a progressão da esteatose é a disfunção mitocondrial hepática (8), que, por sua vez, parece ter como causa principal a produção excessiva de espécies reativas de oxigênio e de aldeídos reativos, que causam dano mitocondrial, gerando um círculo vicioso (9). O estudo de Li e cols. (10) mostrou que o palmitato é um potente indutor da geração de espécies reativas de oxigênio mitocondriais. Ademais, este ácido graxo induz apoptose de hepatócitos (11), que é uma manifestação evidente e um preditor independente de esteato-hepatite não alcoólica (12). Portanto, a quantidade significativamente maior de palmitato encontrada no grupo $\mathrm{TAGC}_{7} 0$ e a correlação linear positiva significativa entre a concentração hepática desse ácido graxo e os graus de $\mathrm{EH}$ observados nos animais dos diferentes grupos são fatores potencialmente deletérios no que diz respeito ao prognóstico da doença.

A concentração significativamente maior de linoleato no grupo $\mathrm{TAGC}_{7} 0$, por sua vez, pode ser explicada pelo maior consumo de óleo de soja, quando comparado aos grupos $\mathrm{TAGC}_{7} 30$ e $\mathrm{TAGC}_{7} 50$. AG poliinsaturados da família $\omega-6$ e $\omega$-3, de 18 a 22 átomos de carbono, ativam mais fortemente todas as isoformas dos receptores ativados por proliferadores de peroxissoma (PPARs) que os AG saturados e monoinsaturados. Adicionalmente, são mais potentes ativadores da oxidação e supressores da síntese de AG e, portanto, da síntese de triacilgliceróis que aqueles últimos (13), o que promoveria um efeito hepatoprotetor contra a esteatose. No entanto, os potenciais efeitos danosos do acúmulo de linoleato, por ser um ácido graxo poliinsaturado e, portanto, mais suscetível à peroxidação lipídica, parecem ter suprimido uma possível ação benéfica.

Com o intuito de investigar a segurança e a tolerabilidade do consumo de ésteres de glicerol com ácido heptanoico, Lucena e cols. (7) realizaram uma avaliação toxicológica do consumo de trieptanoína, em proporções cetogênicas, em ratos. Os autores concluíram que, apesar do quadro de $\mathrm{EH}$ observado, de características mais brandas que aquelas encontradas no presente estudo, a dieta cetogênica rica em trieptanoína não promoveu efeitos metabólicos adversos nos animais. Desdobramentos de tal trabalho, a exemplo da determinação do perfil em AG do tecido hepático, atualmente em curso, poderão auxiliar na elucidação da repercussão do consumo de trieptanoína, no contexto da EH, dada a maior concentração de lipídios dietéticos. 
Agradecimentos: Agradecemos aos professores Severino Matias de Alencar (ESALQ-USP), Edma Carvalho de Miranda e Denise Maria Pinheiro (IQB-UFAL) pelas análises cromatográficas; ao professor Cyro Rego Cabral Jr. (FANUT-UFAL) pelo auxílio na análise estatística; e à Fernanda Galdino de Oliveira e Mércia Cruz Santos pelo apoio na execução do trabalho.

Declaração: os autores declaram não haver conflitos de interesse científico neste estudo.

\section{REFERÊNCIAS}

1. Silva MAF, Ataide TR, Oliveira SL, Sant'Ana AEG, Cabral Jr CR, Balwani MC, et al. Efeito hepatoprotetor do consumo crônico de dieptanoína e trieptanoína contra a esteatose em ratos. Arq Bras Endocrinol Metab. 2008;52:1145-55.

2. Ataíde TR, Oliveira SL, Silva FM, Vitorino-Filha LG, Tavares MC, Sant'Ana AEG. Toxicological analysis of the chronic consumption of diheptanoin and triheptanoin in rats. Int J Food Sci and Technol. 2009;44:484-92.

3. Hulbert AJ, Turner N, Storlien LH, Else PL. Dietary fats and membrane function: implications for metabolism and disease. Biol Rev. 2005;80:155-69.

4. Pan DA, Storlien LH. Dietary lipid profile is a determinant of tissue phospholipid fatty acid composition and rate of weight gain in rats. J Nutr. 1993;123(3):512-9.
5. Reeves PG. Components of the AIN-93 diets as improvements in the AIN-76 a diet. J Nutr. 1997;127:838-41.

6. Gilani GS, Ratnayake WM, Brooks SP, Botting HG, Plouffe LJ, Lampi BJ. Effects of dietary protein and fat on cholesterol and fat metabolism in rats. Nutr Res. 2002;22:297-311.

7. Lucena ALM, Oliveira SL, Ataíde TR, Silva AX, Cabral Jr. CR, Oliveira MAR, et al. High-fat diet based on trienantin has no adverse metabolic effects in rats. Eur J Lipid SciTechnol. 2010;112(2):166-72.

8. Oliveira CPMS, Coelho AMM, Barbeiro HV, Lima VMR, Soriano F, Ribeiro $C$, et al. Liver mitochondrial dysfunction and oxidative stress in the pathogenesis of experimental nonalcoholic fatty liver disease. Braz J Med Biol Res. 2006;39(2):189-94.

9. Begriche K, Igoudjil A, Pessayre D, Fromenty B. Mitochondrial dysfunction in NASH: causes, consequences and possible means to prevent it. Mitochondrion. 2006;6:1-28.

10. Li Z, Berk M, McIntyreTM, Gores GJ, Feldstein AE. The lysosomalmitochondrial axis in free fatty acid-induced hepatic lipotoxicity. Hepatology. 2008;47(5)1495-503.

11. Gentile CL, Pagliassotti MJ. The role of fatty acids in the development and progression of nonalcoholic fatty liver disease. J Nutr Biochem. 2008;19:567-76.

12. Wieckowska A, Zein NN, Yerian LM, Lopez AR, McCullough AJ, Feldstein AE. In vivo assessment of liver cell apoptosis as a novel biomarker of disease severity in nonalcoholic fatty liver disease. Hepatology. 2006;44:27-33.

13. Clarke SD, Thuillier P, Baillie RA, Sha X. Peroxisome proliferatoractivated receptors: family lipid-activated transcription factors. Am J Clin Nutr. 1999;70:566-71. 